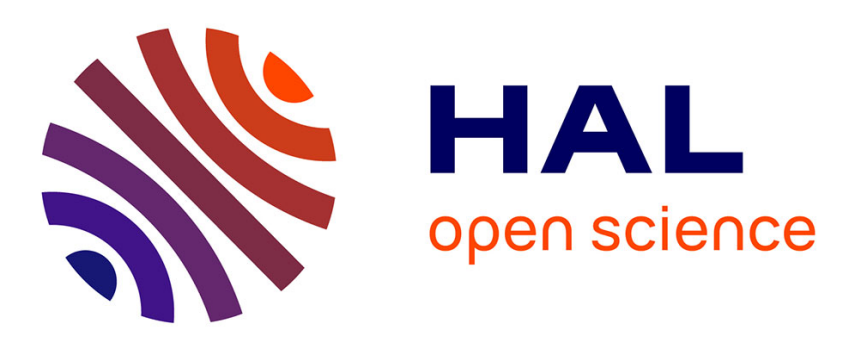

\title{
Molecular Dynamics Simulations of Gas-Expanded Liquids
}

\author{
Emanuel Granero Fernandez, Jean-Stéphane Condoret, Vincent Gerbaud, \\ Yaocihuatl Medina-González
}

\section{- To cite this version:}

Emanuel Granero Fernandez, Jean-Stéphane Condoret, Vincent Gerbaud, Yaocihuatl MedinaGonzález. Molecular Dynamics Simulations of Gas-Expanded Liquids. Molecular dynamics simulations of Gas-Expanded Liquids in Computer Aided Chemical Engineering, pp.175-180, 2017, 10.1016/B978-0-444-63965-3.50031-3 . hal-02380504

\section{HAL Id: hal-02380504 https://hal.science/hal-02380504}

Submitted on 10 Dec 2020

HAL is a multi-disciplinary open access archive for the deposit and dissemination of scientific research documents, whether they are published or not. The documents may come from teaching and research institutions in France or abroad, or from public or private research centers.
L'archive ouverte pluridisciplinaire HAL, est destinée au dépôt et à la diffusion de documents scientifiques de niveau recherche, publiés ou non, émanant des établissements d'enseignement et de recherche français ou étrangers, des laboratoires publics ou privés. 
Antonio Espuña, Moisès Graells and Luis Puigjaner (Editors), Proceedings of the $27^{\text {th }}$ European Symposium on Computer Aided Process Engineering - ESCAPE 27

October $1^{\text {st }}-5^{\text {th }}, 2017$, Barcelona, Spain $@ 2017$ Elsevier B.V. All rights reserved.

\title{
Molecular Dynamics Simulations of Gas-Expanded Liquids
}

\author{
Emanuel Granero Fernandez ${ }^{\mathrm{a}}$, Jean-Stèphane Condoret ${ }^{\mathrm{a}}$, Vincent Gerbaud ${ }^{\mathrm{a}}$, \\ Yaocihuatl Medina Gonzalez ${ }^{\text {a* }}$ \\ ${ }^{a}$ Laboratoire de Génie Chimique, Université de Toulouse, CNRS, INPT, UPS, 4 Allée \\ Emile Monso, Toulouse F-31030, France \\ yaocihuatl.medinagonzalez@ensiacet.fr \\ vincent.gerbaud@ensiacet.fr
}

\begin{abstract}
Gas-expanded Liquids (GXL's) are liquids whose volume is expanded by a pressurized gas. The incorporation of the gaseous compound and the expansion of the liquid phase lead to changes in solvation and transport properties of the new expanded phase.

This work aims at developing a Molecular Dynamics (MD) computational study for liquid methyl and ethyl acetates when expanded by $\mathrm{CO}_{2}$ at pressures up to 120 bars and at temperatures between 298 and 393 K. Especially, density and viscosity of the liquid expanded phase were calculated by MD simulations. Good agreement with existing literature data has been obtained ascertained the validity of the method
\end{abstract}

Keywords: molecular dynamics, alkyl acetates, viscosity, density.

\section{Introduction}

With the perspective of finding alternative benign media for different applications, solvent engineering represents an interesting alternative to propose innovative solutions to industrial problems. Gas-expanded liquids (GXLs), in particular $\mathrm{CO}_{2}$-expanded liquids (CXLs), which are liquids whose volume is expanded by pressurized $\mathrm{CO}_{2}$, represent a very promising strategy to perform solvent engineering.

A number of properties, including solvation properties, can be tuned by the addition of $\mathrm{CO}_{2}$ to a liquid solvent (Jessop and Subramaniam, 2007) allowing the use of CXLs as "solubility switchers". In many cases, solutes that are soluble in $\mathrm{CO}_{2}$-expanded solvents will precipitate when $\mathrm{CO}_{2}$ is removed and vice versa. For example, the addition of $\mathrm{CO}_{2}$ to a biphasic system of a fluorinated solvent and an organic solvent causes the phases to become miscible (West et al., 2004). Opposite effect is seen in cases of water-soluble organics and an aqueous phase, where the addition of $\mathrm{CO}_{2}$ forces the phases to split ( $\mathrm{Lu}$ et al., 2004). Both systems may have applications in catalyst recycle and/or product recovery. Knowledge of phase equilibrium properties but also of transport properties and in particular viscosity, is evidently important to design processes exploiting the peculiar behavior of these two-phase systems.

Moreover, high-pressure experimental determinations of density and viscosity of systems involving hazardous compounds and/or at harsh conditions of pressure and temperature are usually problematic. As an alternative, numerical experiments with the help of molecular simulation, like Molecular Dynamics (MD) have gained interest in 
recent years as the performance of computational tools is continuously improving. In particular, MD simulations have gained enormous progress in terms of 1) simulation methods, 2) understanding of complex phenomena, and 3) ability to model extremely complex systems.

MD simulations accuracy is highly dependent on the proper representation of the interaction forces acting on the molecules. This depends on the choice of a suitably parametrized force field and on a statistically representative sampling of the states of the system. Previous works on $\mathrm{CO}_{2}$-expanded acetates (Smith et al., 1998; Aida et al., 2010) describe some of these system properties, such as the Vapor-Liquid Equilibrium curves and the expanded phase density. However, no data were found about the viscosity of the alkyl acetates $/ \mathrm{CO}_{2}$ expanded phase, probably due to the difficulty of high-pressure expanded phase determinations.

Hence, this work rather to present a new methodology of properties calculation, intends to emphasize an alternative application for MD simulations, as it is to numerically predict equilibria and transport properties of $\mathrm{CO}_{2}$-expanded acetates. The MD method and its accuracy were first evaluated for other $\mathrm{CO}_{2}$-expanded solvents before predicting the densities and the viscosities of systems involving methyl and ethyl acetate. Indeed, Acetone $\left(\mathrm{C}_{3} \mathrm{H}_{6} \mathrm{O}\right)$ and Decane $\left(\mathrm{C}_{10} \mathrm{H}_{22}\right)$ where chosen for this task for two main reasons: The availability of $\mathrm{CO}_{2}$-expanded phase viscosity data and the presence of hydrocarbon chain in decane and the carbonyl group in acetone, both groups found in alkyl acetates. It is worth to note that accurate results for $\mathrm{CO}_{2}$-expanded acetates systems will open up the possibility to study more complex $\mathrm{CO}_{2}$-expanded systems, for which no experimental data exist.

\section{Method}

\subsection{Theory background}

The fluctuation-dissipation theorem explains how transport coefficients associated to irreversible processes can be described using reversible microscopic fluctuations (Kubo, 1966). The Green-Kubo (Green, 1954; Kubo, 1957) relations give the exact mathematical expression for transport coefficients in terms of integrals of timecorrelation functions.

In the standard Green-Kubo method shear viscosity can be calculated by integrating the autocorrelation function of the stress tensor over time (1):

$\eta=\frac{V}{k_{\mathrm{B}} T} \lim _{\tau \rightarrow \infty} \int_{0}^{\tau} \mathrm{d} t\left\langle P_{x y}(t) P_{x y}(0)\right\rangle$

Where $\left\langle P_{x y}(\mathrm{t}) P_{x y}(0)\right\rangle$ is the correlation function of the xy component of the stress tensor, $\mathrm{V}$ is the volume of the simulation box, $k_{B}$ is the Boltzmann constant, $T$ is the absolute temperature and $t$ is the time.

\subsection{Simulation details}

The required liquid phase composition data at equilibrium was extracted from literature and from our own determinations.

MD computations were carried out using the Materials Processes and Simulations (MAPS) Suite from Scienomics and in the Large-scale Atomic/Molecular Massively 
Parallel Simulator (LAMMPS) code from Sandia National Laboratories. The "Amber_Cornell_Extended" force field was selected (Table 1).

Table 1: Amber_Cornell_Extended Force field bond and pairwise potentials

\begin{tabular}{|c|c|c|c|}
\hline Bond & Angle & Improper & Dihedral (hybrid) \\
\hline$E=K\left(r-r_{o}\right)^{2}$ & $E=K\left(\theta-\theta_{o}\right)^{2}$ & $E=K[1+\cos (n \varnothing-d)]$ & \multirow{3}{*}{$\begin{array}{c}E=K\left(X-X_{o}\right)^{2} \\
E=\sum_{i=1, m} K_{i}\left[1.0+\cos \left(n_{i} \emptyset-d_{i}\right)\right]\end{array}$} \\
\hline VdW : L-J ${ }_{12-6}$ & & Coulombic & \\
\hline$L J(r)=4 \epsilon\left\lceil\left(\frac{\sigma}{r}\right.\right.$ & $\left.-\left(\frac{\sigma}{r}\right)^{6}\right] * S(r)$ & $C(r)=\frac{C q_{i} q_{j}}{\epsilon r}$ & \\
\hline
\end{tabular}

Table 2: Fitted atomic center charges

\begin{tabular}{|c|c|c|c|c|c|}
\hline Atom & AM1 & ESP & Atom & AM1 & ESP \\
\hline Acetone & & & Decane & & \\
\hline $\mathrm{C}$ & $-0,2041$ & $-0,522162$ & $\mathrm{C}$ & $-0,21$ & $-0,326006$ \\
\hline $\mathrm{C} 1$ & 0,5631 & 0,811667 & $\mathrm{C} 1$ & $-0,159$ & 0,213133 \\
\hline $\mathrm{C} 2$ & $-0,2041$ & $-0,512053$ & $\mathrm{C} 2$ & $-0,158$ & 0,05664 \\
\hline $\mathrm{O}$ & $-0,5311$ & $-0,580332$ & C3 & $-0,158$ & $-0,085466$ \\
\hline $\mathrm{H}$ & 0,063033 & 0,141684 & $\mathrm{C} 4$ & $-0,158$ & 0,11713 \\
\hline $\mathrm{H} 1$ & 0,063033 & 0,131853 & C5 & $-0,158$ & 0,12006 \\
\hline $\mathrm{H} 2$ & 0,063033 & 0,131853 & C6 & $-0,158$ & $-0,087939$ \\
\hline $\mathrm{H} 3$ & 0,063033 & 0,138492 & $\mathrm{C} 7$ & $-0,158$ & 0,057575 \\
\hline $\mathrm{H} 4$ & 0,063033 & 0,129499 & $\mathrm{C} 8$ & $-0,159$ & 0,213154 \\
\hline H5 & 0,063033 & 0,129499 & C9 & $-0,21$ & $-0,324668$ \\
\hline & & & $\mathrm{H}$ & 0,072 & 0,068357 \\
\hline Methyl Acetate (MA) & & & $\mathrm{H} 1$ & 0,072 & 0,068324 \\
\hline $\mathrm{C}$ & $-0,1501$ & $-0,664509$ & $\mathrm{H} 2$ & 0,072 & 0,075387 \\
\hline $\mathrm{C} 1$ & 0,6291 & 0,915207 & H3 & 0,078 & $-0,040085$ \\
\hline $\mathrm{O}$ & $-0,4449$ & $-0,433813$ & $\mathrm{H} 4$ & 0,078 & $-0,040075$ \\
\hline $\mathrm{C} 2$ & 0,1267 & 0,0011 & H5 & 0,079 & $-0,018183$ \\
\hline O1 & $-0,541$ & $-0,594817$ & H6 & 0,079 & $-0,018193$ \\
\hline $\mathrm{H}$ & 0,0757 & 0,180868 & $\mathrm{H} 7$ & 0,079 & $-0,001635$ \\
\hline H1 & 0,0757 & 0,178806 & H8 & 0,079 & $-0,001689$ \\
\hline $\mathrm{H} 2$ & 0,0757 & 0,17922 & H9 & 0,079 & $-0,034637$ \\
\hline $\mathrm{H} 3$ & 0,0617 & 0,084701 & $\mathrm{H} 10$ & 0,079 & $-0,034645$ \\
\hline $\mathrm{H} 4$ & 0,0447 & 0,076499 & H11 & 0,079 & $-0,035151$ \\
\hline H5 & 0,0447 & 0,076736 & H12 & 0,079 & $-0,035188$ \\
\hline & & & H13 & 0,079 & $-0,001125$ \\
\hline Ethyl Acetate (EA) & & & H14 & 0,079 & $-0,001192$ \\
\hline $\mathrm{C}$ & $-0,1501$ & $-0,603183$ & H15 & 0,079 & $-0,018348$ \\
\hline $\mathrm{C} 1$ & 0,6311 & 0,910216 & H16 & 0,079 & $-0,018373$ \\
\hline $\mathrm{O}$ & $-0,4469$ & $-0,51646$ & H17 & 0,078 & $-0,040213$ \\
\hline $\mathrm{C} 2$ & 0,1384 & 0,356665 & H18 & 0,078 & $-0,040178$ \\
\hline $\mathrm{C} 3$ & $-0,1001$ & $-0,34453$ & H19 & 0,072 & 0,075719 \\
\hline $\mathrm{O} 1$ & $-0,544$ & $-0,613058$ & $\mathrm{H} 20$ & 0,072 & 0,068759 \\
\hline $\mathrm{H}$ & 0,0517 & 0,011202 & $\mathrm{H} 21$ & 0,072 & 0,06875 \\
\hline H1 & 0,0517 & 0,011164 & & & \\
\hline $\mathrm{H} 2$ & 0,0757 & 0,16283 & & & \\
\hline $\mathrm{H} 3$ & 0,0757 & 0,167183 & & & \\
\hline $\mathrm{H} 4$ & 0,0757 & 0,167011 & & & \\
\hline H5 & 0,0467 & 0,078193 & & & \\
\hline H6 & 0,0477 & 0,106401 & & & \\
\hline $\mathrm{H} 7$ & 0,0477 & 0,106364 & & & \\
\hline
\end{tabular}


The geometries for all the molecules were optimized at the HF/6-31G+** level by using DFT quantum calculations. The partial charges were then fitted using two separate methods. The first one used the Electrostatic Potential method (ESP) on the optimized geometries at the HF/6-31G+** level. The second one used the AM1-BBC method, which includes the optimization of the initial geometry at the AM1 level, and after the calculation of the Mulliken charges, the BCC bond correction was applied (Semi empirical Quantum Mechanics). The fitted charges are displayed in Table 2.

After repeated tests, a number of molecules per box and a finite time of equilibration, production and integration were defined. The simulated boxes were set with periodic boundaries in all directions containing a total of 1000 molecules in the IsobaricIsothermal ensemble. The simulations were performed as follows: NPT equilibration and density production runs of 1,200,000 steps. Afterwards, NVT equilibration runs for 400,000 steps were followed by NVE viscosity production runs for 1,200,000 steps. All runs were performed with a timestep of $1 \mathrm{fs}$. The L-J and Coulombic cut-off was set to $8 \AA$ with a switching distance of $\mathrm{r}=12 \AA$. The simulations were started with randomly assigned velocities, the total momentum of the system was set to zero and Newton's equations of motion were solved with the standard Velocity-Verlet algorithm. Calculations were performed with the EOS super-calculator of CALMIP.

\section{Results and Discussion}

\subsection{Density}

Densities obtained by MD are shown in Figure 1 as function of $\mathrm{CO}_{2}$ molar fraction at different temperatures and pressures up to 120 bars, together with literature experimental data.

a)

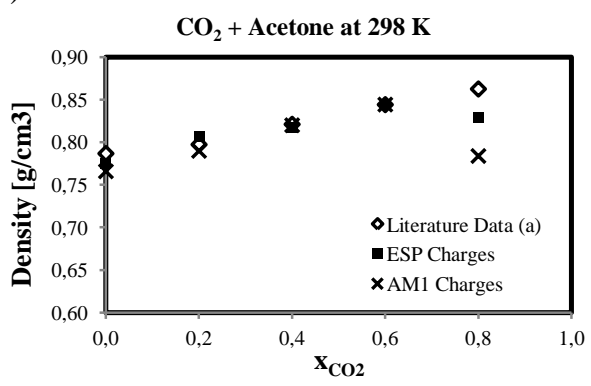

c)

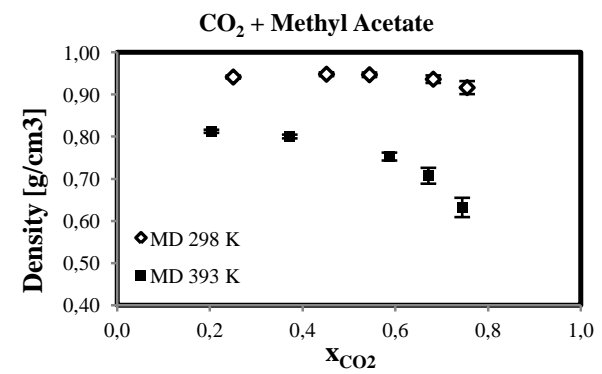

b)

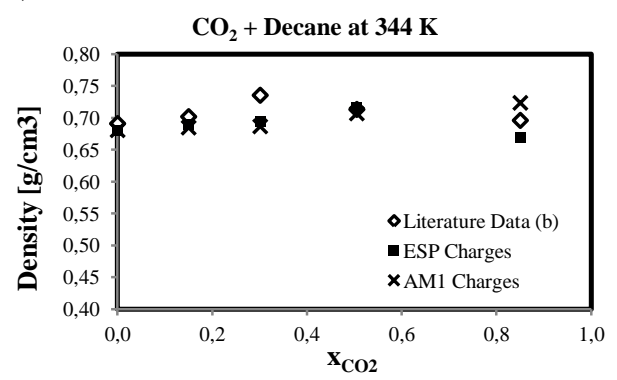

d)

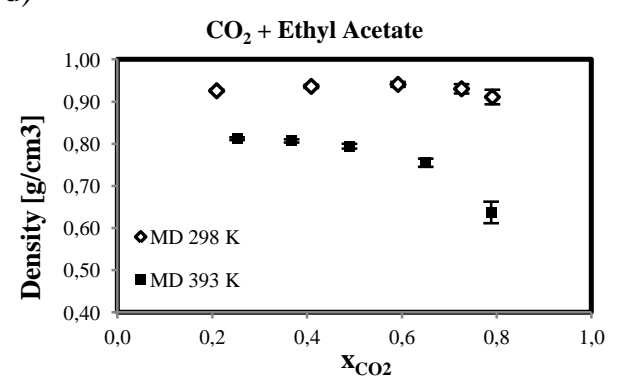


Figure 1: $\mathrm{CO}_{2}$-expanded density $\left(\mathrm{g} / \mathrm{cm}^{3}\right)$ vs $\mathrm{CO}_{2}$ molar fraction for all studied systems. Literature refs: (a) (Sih and Foster 2008); (b) (Cullick and Mathis 1984).

In Figures 1 c) and d) two distinct zones can be observed. Firstly, the density increases monotonically as the $\mathrm{CO}_{2}$ solubilizes. Then, after a certain point $\left(\mathrm{x}_{\mathrm{CO} 2} \approx 0.7\right)$, higher $\mathrm{CO}_{2}$ molar fraction produces a drastic volume increment and the consequent decrease in density. Error bars were calculated as the Standard Deviation between the average values every 10.000 steps. This behavior has been explained by an increase in free volume observed in some CXLs ( $\mathrm{Li}$ and Maroncelli, 2006), which would be responsible for their fluidity and solvation properties. Indeed, the initial solvent intermolecular spaces can first host the $\mathrm{CO}_{2}$ to some extent, producing an imperceptible increment in volume. Then, after a certain threshold in $\mathrm{CO}_{2}$, its solubilisation induces a rapid volume expansion. At this point, the model lacks of accuracy with increasing $\mathrm{CO}_{2}$ concentration because of its molecular quadrupole, and the error in calculated values against literature increases.

\subsection{Viscosity}

Calculated viscosities are shown in Figure 2 as function of $\mathrm{CO}_{2}$ molar fraction at different temperatures and pressures up to 120 bars. Literature data is plotted when available. Figure 2 shows a) $\mathrm{CO}_{2}+$ Acetone and b) $\mathrm{CO}_{2}+$ Decane systems for a single $\mathrm{T}$ with both charges sets; and c) $\mathrm{CO}_{2}+\mathrm{MA}$ and d) $\mathrm{CO}_{2}+\mathrm{EA}$ systems viscosity at different temperatures as a function of $\mathrm{x}_{\mathrm{CO} 2}$. For these two systems, no literature data was found concerning viscosity. Standard deviation for all systems falls under 5 E-10 due to integration over time smoothing. The observed viscosities behavior coherent with previously reported $\mathrm{CO}_{2}$-expanded systems ( $\mathrm{Li}$ and Maroncelli 2006). In these systems, the viscosity decreases as a quasi linear function of $\mathrm{CO}_{2}$ mole fraction. This general behavior is explained by the decrease of electrostatic forces between the solvent molecules due to the interposing $\mathrm{CO}_{2}$ molecules, clustering around carbonyl groups (Aida et al., 2010). No significant differences can be appreciated between ESP and AM1 charges, showing that the Coulombic energies have a smaller impact on pressure fluctuation than L-J parameters.

a)

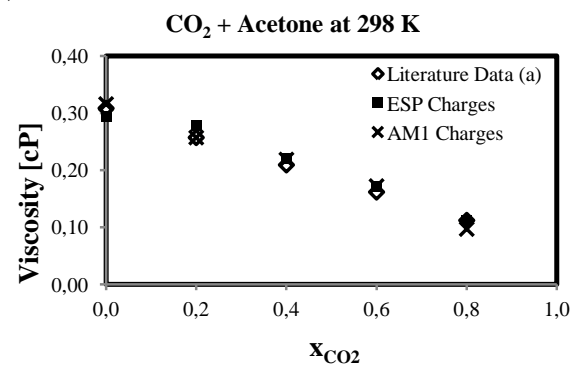

b)

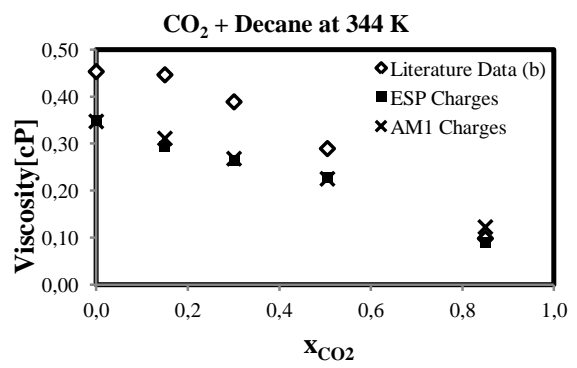


c)

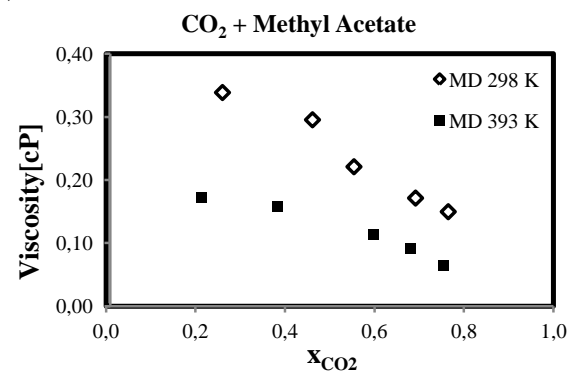

d)

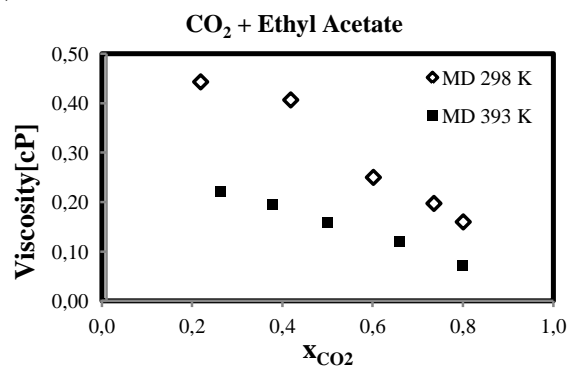

Figure 2: Viscosity (cP) vs $\mathrm{CO}_{2}$ molar fraction of $\mathrm{CO}_{2}$-expanded acetone, decane, MA and EA. Refs a) (Sih and Foster 2008) b) (Cullick and Mathis, 1984),

\section{Conclusion}

MD simulations and Green-Kubo stress correlation function were used to predict densities and viscosities of $\mathrm{CO}_{2}$-expanded ethyl and methyl acetates systems. The technique was also assessed as relatively accurate by comparing simulated densities and viscosities of $\mathrm{CO}_{2}$-expanded acetone and decane systems to literature data. This simple approach using existing MD potentials and DFT charges calculation can be used now to obtain other properties of other promising $\mathrm{CO}_{2}$-expanded fluids.

\section{Acknowledgment}

This work has been carried out with help of the CALMIP supercomputer facility (project $\left.\mathrm{n}^{\circ} \mathrm{P} 1535\right)$. Authors deeply thank CALMIP for the hours allocated to this project.

\section{References}

T. Aida, T. Aizawa, M. Kanakubo, and H. Nanjo, (2010). Analysis of volume expansion mechanism of CO2-acetate systems at $40{ }^{\circ} \mathrm{C}$. J. Supercrit. Fluids, 55(1), 56-61.

A. S. Cullick, and M. L. Mathis, (1984). Densities and Viscosities of Mixtures of Carbon Dioxide and n-Decane from 310 to $403 \mathrm{~K}$ and 7 to $30 \mathrm{MPa}$. Journal of Chem. and Eng. Data, 29(4), 393-396. http://doi.org/10.1021/je00038a008

M. S. Green, (1954). Markoff Random Processes and the Statistical Mechanics of Time-Dependent Phenomena. II. Irreversible Processes in Fluids. J. Chem. Phys., 22(3), 398413.

P. G. Jessop, and B. Subramaniam, (2007). Gas-expanded liquids. Chem. Rev., 107(6), 26662694. http://doi.org/10.1021/cr040199o

R. Kubo, (1957). Statistical-Mechanical Theory of Irreversible Processes. I. General Theory and Simple Applications to Magnetic and Conduction Problems. J. Phys. Soc. Jpn., 12(6), 570 586. http://doi.org/10.1143/JPSJ.12.570

R. Kubo, (1966). The fluctuation-dissipation theorem. Reports on Progress in Physics, 29(1), 255.

H. Li, and M. Maroncelli, (2006). Solvation and Solvatochromism in CO2-Expanded Liquids. 1. Simulations of the Solvent Systems CO2 + Cyclohexane, Acetonitrile, and Methanol. http://doi.org/10.1021/JP064166J 
J. Lu, M. J. Lazzaroni, J. P. Hallett, A. S. Bommarius, C. L. Liotta, and C. A. Eckert, (2004). Tunable Solvents for Homogeneous Catalyst Recycle. Ind. Eng. Chem. Res., 43 (7), 15861590

R. Sih, and N. R. Foster, (2008). Viscosity measurements on saturated gas expanded liquid systems-Acetone and carbon dioxide. J. Supercrit. Fluids, 47(2), 233-239.

R. L. Smith, T. Yamaguchi, T. Sato, H. Suzuki, and K. Arai, (1998). Volumetric behavior of ethyl acetate, ethyl octanoate [...] in the presence of supercritical CO2. J. Supercrit. Fluids, 13(1-3), 29-36.

K. N. West, J. P. Hallett, R. S. Jones, D. Bush, C. L. Liotta, and C. A. Eckert (2004). CO2Induced Miscibility of Fluorous and Organic Solvents for Recycling Homogeneous Catalysts. Ind. Eng. Chem. Res., 43 (16), pp 4827-4832. 